\title{
A lidar for water vapour measurements in daytime at Lampedusa, Italy
}

\author{
Paolo Tini Brunozzi $(*)$ and Franco Marenco $\left({ }^{* *}\right)$ \\ ENEA-Casaccia, GEM-CLIM, S. Maria di Galeria (RM), Italy
}

\begin{abstract}
ENEA is planning to develop a lidar system for measurement of the vertical profile of water vapour mixing ratio in daytime at a remote site, the Station for Climate Observations located in Lampedusa, Italy. The Raman lidar technique has been retained because of its experimental simplicity with respect to DIAL, and the UV spectral range has been chosen because Raman cross-sections and detector efficiencies are larger. For a wavelength larger than $\sim 300 \mathrm{~nm}$ the signal is limited in daytime by sky background, but extinction is acceptable, and the aims of the system can be reached with a strong laser source. The $355 \mathrm{~nm}$ wavelength of a frequency-tripled Nd:YAG laser has been retained as this laser source permits to reach a large pulse energy while keeping the system simple to operate. Geometrical form factor calculations need to be performed to evaluate the near-range overlap between the laser beam and the field-of-view of the receiver. Among several options, a dual-receiver system has been retained to account for the several orders of magnitude expected in the backscattered signal intensity: a smaller receiver, with a primary mirror of $200 \mathrm{~mm}$ diameter for the $0.2-1 \mathrm{~km}$ range, and a larger $500 \mathrm{~mm}$ receiver for the $1-3 \mathrm{~km}$ range.
\end{abstract}

Key words Raman lidar-water vapour

\section{Introduction}

Water vapour plays an important role in several meteorological and climate processes, and it can be considered one of the most important substances present in the atmosphere. Water vapour influences the radiation field directly by acting as a greenhouse gas (absorption in the infrared part of the spectrum). Due to cloud formation, evaporation and precipitation, water in the vapour and condensed states affects the transport of latent heat, with effects on dynamics

Mailing address: Dr. Franco Marenco, ENEA-Casaccia, GEM-CLIM, Via Anguillarese 301, 00060 S. Maria di Galeria (RM), Italy; e-mail: franco.marenco@casaccia.enea.it

(*) Present address: ISIC, Foligno (PG), Italy.

(**) Present address: Dipartimento di Fisica, Università di Genova, Italy. and meteorology. Clouds also influence the radiation budget, especially through scattering of visible light and increasing of the terrestrial albedo.

Water vapour profiles can be measured with active sensors, such as lidar. A lidar is based on the emission of light pulses into the atmosphere and on the measurement of the radiation backscattered by the atmospheric layers under investigation. The original idea of probing the atmosphere with light beams dates back to Tyndall (1869), but it is only with the advent of laser technology that the lidar began to be used more systematically (Fiocco and Smullin, 1963; Ligda, 1963). Since then, the field has progressed rapidly and new systems have been developed (Hinkley, 1976; Ansmann et al., 1997; Burke et al., 1998; Bisson et al., 1999; Ellsworth et al., 2000; Dabas et al., 2001; Wulfmeyer and Walther, 2001). The advantages of the lidar technique reside in the high vertical and temporal resolutions, with the possibility to make continuous measurements with a 
large repetition rate at a relatively low cost of operation. Simulation of system performance is a useful method for determining the important experimental parameters (see, among others, Whiteman et al., 2001; Wulfmeyer and Walther, 2001a,b).

The National Agency for New Technology, Energy and Environment (ENEA) runs the Station for Climate Observations located in Lampedusa, Italy $\left(35.5^{\prime} \mathrm{N}, 12.6^{\prime} \mathrm{E}\right)$. Several instruments are installed in the station and monitor several important atmospheric parameters such as the concentration of greenhouse gases, total ozone, aerosol load, solar radiation and meteorological parameters (Chamard et al., 1999; di Sarra et al., 2001; Marenco et al., 2002; Meloni et al., 2003).

ENEA is planning to install in Lampedusa a lidar system for measurement of the vertical profile of water vapour mixing ratio, based on the Raman technique: this technique is based on a shift in received wavelength to identify the scattering molecule. Raman lidar measurements of water vapour have been performed by Vaughan et al. (1988); Whiteman et al. (1992); Goldsmith et al. (1998); Bisson et al. (1999), and many others. Raman lidar measurements in daytime are somewhat critical due to low backscattered signal and large background. However, quite powerful systems have been deployed recently and have shown that it is possible to reach the range of $5-7 \mathrm{~km}$ in daytime (Goldsmith et al., 1998; Bisson et al., 1999). The aim of this paper is to perform a simple numerical simulation of system performance, based on realistic component properties. Our sizing considerations are based on the goal to reach the $1 \mathrm{~km}$ vertical range, with a signal-to-noise ratio of at least 7 , in daytime when averaging over two minutes temporal resolution; to reach $3 \mathrm{~km}$ in daytime with a 30 min temporal resolution, and to reach the tropopause at nightime. We are aware, however, that the difficulty of reaching larger altitudes may constitute a limitation for the study of planetary boundary layer meteorology.

\section{Lidar system simulation}

Raman lidar allows profiles of mixing ratio $w$ to be determined by taking the ratio of Raman backscatter by water vapour to Raman backscatter by one of the well mixed gases such as nitrogen (Whiteman et al., 1992). The emitted wavelength was chosen based on several parameters: a) water vapour backscattering cross-section; b) atmospheric extinction; c) sky background intensity; d) laser source availability and power, and e) detector efficiency. For Raman scattering, the backscattering cross-section follows a $\lambda^{-4}$ law, similarly to Rayleigh scattering: therefore, if we want to put all chances on our side, short wavelengths are more interesting and the ultraviolet band is most indicated. Choosing to work in the UV also achieves a better detector efficiency than in the visible and near infrared bands. When working in the UV wavelength range, however, the absorption spectrum of ozone must be considered, since it dominates the atmospheric radiation field. For $\lambda<300 \mathrm{~nm}$ we have the «solar blind» case, since ozone absorption prevents solar radiation from reaching the ground; however, the signal is strongly reduced by extinction due to even small concentrations of ozone in the troposphere. For this reason «solar blind» systems are confined to a 1-2 km vertical range (Renaut et al., 1980; Petri et al., 1982). We have therefore confined ourselves to $\lambda>300 \mathrm{~nm}$. The weakness of the signal due to the small water vapour backscattering cross-section, and the large sky background put a constraint on laser output power, which must be as large as possible. The $355 \mathrm{~nm}$ wavelength was chosen due to the availability of the Nd:YAG laser with Third Harmonic Generation: this source is in fact simple to use and quite powerful.

Two important parameters are the telescope area and Field-Of-View (FOV). A large receiver aperture determines a larger signal and a narrow FOV implies a smaller sky background: therefore, at a first approach it would seem necessary to have a large telescope with a narrow FOV. On the other hand, however, such a receiver may not be suitable for observing the nearby atmospheric layers, due to incomplete overlap between transmitted beam and receiver field-of-view. The choice of telescope area and FOV is the result of a balance between the need to reach far atmospheric layers and the need to view the nearby layers: it is therefore important to evaluate the geometrical form factors for 
Table I. Inputs used for geometrical form factor calculations and results.

\begin{tabular}{lcc}
\hline \hline \multicolumn{1}{c}{ Telescope } & Small & Large \\
\hline Beam divergence $(\mathrm{mrad})$ & 0.1 & 0.1 \\
Beam diameter $(\mathrm{mm})$ & 50 & 50 \\
Primary diameter $(\mathrm{mm})$ & 200 & 500 \\
Secondary diameter $(\mathrm{mm})$ & 50 & 120 \\
Focal length $(\mathrm{mm})$ & 600 & 1250 \\
Diaphragm diameter $(\mathrm{mm})$ & 0.6 & 0.5 \\
Field-of-view (mrad) & 1 & 0.4 \\
\hline Half overlap range $(\mathrm{m})$ & 150 & 910 \\
Full overlap range $(\mathrm{m})$ & 280 & 1830
\end{tabular}

different telescopes. Such calculations were made according to Halldorsson and Langerholc (1978), using a computer code by Vincenzo Santacesaria (see e.g., Santacesaria et al., 1998). A coaxial geometry was considered, and we found that two different telescopes $(200 \mathrm{~mm}$ and $500 \mathrm{~mm}$ in diameter, with different fields-of-view) must be considered for entirely viewing the $0.2-3 \mathrm{~km}$ interval (see table I). Using two telescopes with different apertures is important not only for geometrical form factor considerations, but also for properly detecting signals varying over several decades.

Figure 1 summarizes the results of the geometrical form factor calculations. What we have labelled «half overlap range» refers to the range where the geometrical form factor is 0.5 . Normally, for elastic backscattering lidar measurements one would consider valid only data obtained with a geometrical form factor of 1 (full overlap). However, since for Raman lidar the ratios between signals measured at the same distance at two wavelengths must be considered, it is admissible to use data obtained at shorter distances. Possible differences in the overlap between the channels can be corrected for by experimentally determining the ratio between them as a function of range before each measurement session, by using Raman nitrogen filters on both channels (Whiteman et al., 1992). This permits us to reach atmospheric layers quite close to the telescope. We conventionally chose to consider the «half overlap range» as the first usable range for water vapour Raman lidar measurements, but we feel that in practice closer ranges can be reached.

The other system constants used in this paper are summarized in table II. Values for pulse energy, pulse repetition frequency and quantum efficiency for commercially available lasers and photomultipliers were assumed. The optical efficiency was conventionally assumed to be $5 \%$, and the range resolution to be $150 \mathrm{~m}$. The zenith

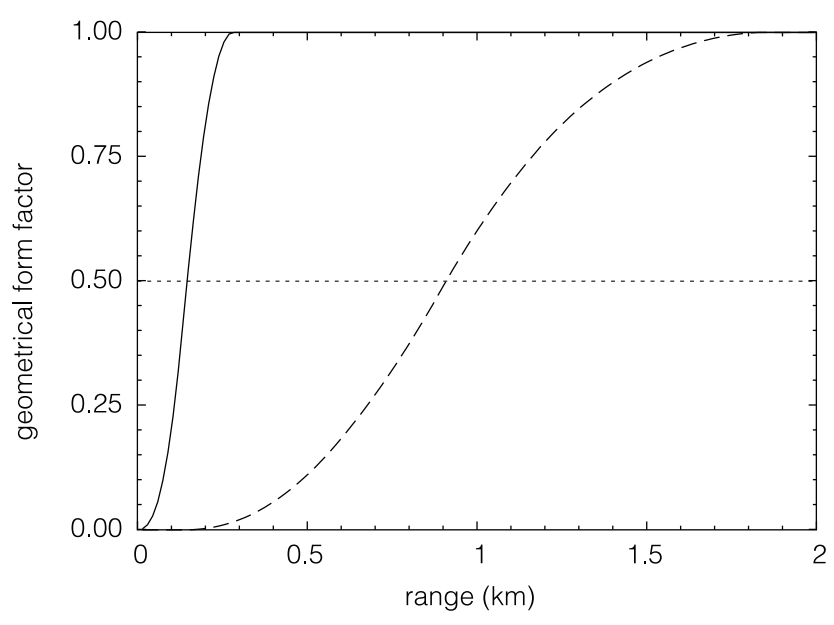

Fig. 1. Geometrical form factors for the two receivers: small telescope (solid line); large telescope (dashed line).

Table II. Lidar system. constants considered for simulation.

\begin{tabular}{lcc}
\hline \hline Emitted wavelenght & 354.7 & $\mathrm{~nm}$ \\
Received wavelenght & 407.5 & $\mathrm{~nm}$ \\
Receiver bandwidth & 0.4 & $\mathrm{~nm}$ \\
Pulse energy & 325 & $\mathrm{~mJ}$ \\
Pulse repetition frequency & 30 & $\mathrm{~Hz}$ \\
Quantum efficiency & 0.25 & \\
Optical efficiency & 0.05 & \\
Vertical resolution & 150 & $\mathrm{~m}$ \\
Zenith sky radiance & 0.32 & $\mathrm{Wm}^{-2} \mathrm{sr}^{-1} \mathrm{~nm}^{-1}$ \\
\hline
\end{tabular}


sky spectral radiance at the received wavelength was derived from measurements taken by a Licor spectrophotometer at Lampedusa at noon in the summer.

The atmospheric profile of water vapour needed for lidar signal calculation, was derived by assuming a 0.005 volume mixing ratio at ground level and an exponential decrease with altitude with $2.5 \mathrm{~km}$ scale height. Profiles of the atmospheric extinction coefficient were derived taking into account Rayleigh scattering and aerosols. Rayleigh scattering profiles were derived from the U.S. Standard Atmosphere et al. (1976), by using the well-known Rayleigh scattering cross-section for the atmosphere (see, e.g., Hinkley, 1976). Aerosol extinction was conventionally accounted for by assuming an aerosol layer near ground, with an optical depth of 0.6 and a uniform vertical profile from ground to $3 \mathrm{~km}$ altitude. Regarding integration time, we assumed 2 min integration for the small telescope, and $30 \mathrm{~min}$ integration for the large one. The resulting simulated lidar signals in daytime conditions, for both the large and the small telescope, are plotted in fig. 2 for the water vapour channel (a random statistical noise has been included to simulate photon count statistics).

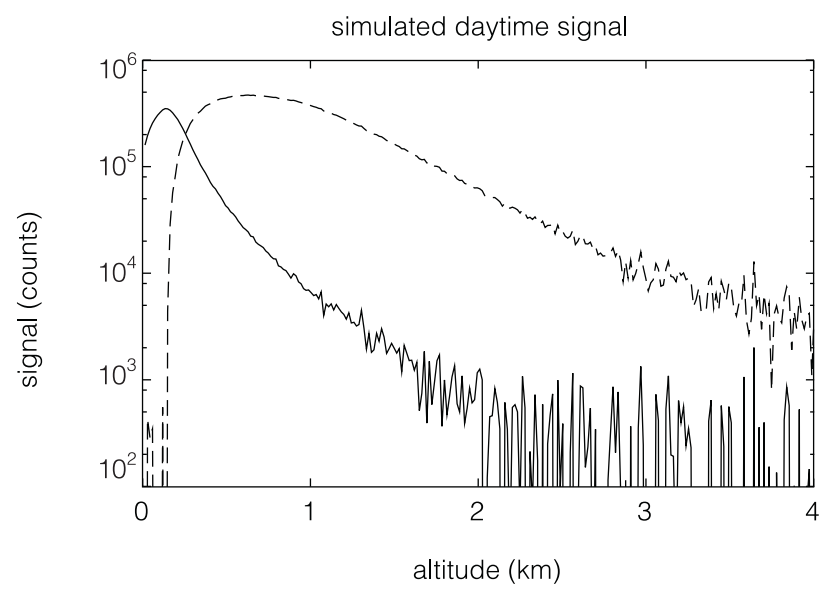

Fig. 2. Simulated water vapour Raman lidar signal for 2 min integration time with the small telescope (solid line), and for $30 \mathrm{~min}$ integration time with the large telescope (dashed line). A random statistical error with Poisson distribution was added to simulate photon count statistics.
The next step was the computation of the Signal-to-Noise Ratio (SNR). Since nitrogen concentration is much larger than water vapour concentration, the simulated signal due to $\mathrm{N}_{2}$ is larger by 2-3 orders of magnitude than the signal due to $\mathrm{H}_{2} \mathrm{O}$, and the uncertainty of the water vapour signal dominates in the global uncertainty on $w$. Therefore, the SNR was estimated by considering the contribution of random noise in the water vapour channel, and neglecting the contribution of the nitrogen channel. We must bear in mind, therefore, than in the final system SNR can be larger due to the neglected contribution. Moreover, possible systematic errors (i.e. on calibration) have not been taken into account. Figure 3 displays the calculated SNR for both receivers in daytime conditions; fig. 4 shows them for nighttime conditions. If we assume that the maximum height achievable is marked by a value of 7 of the SNR (i.e. a $15 \%$ error on mixing ratio), we can see that the goals stated in the introduction can be approached with this hypothetical system, but without full achievement.

With the smaller receiver, thanks to its small diameter, a partial overlap can be achieved in the very near layers: the geometrical form factor is equal to 0.1 at $75 \mathrm{~m}, 0.5$ at $150 \mathrm{~m}$, and 1 (full overlap) starting at $300 \mathrm{~m}$. With 2-min integration, however, the signal decreases quite strongly, and SNR decreases to 7 at around $1 \mathrm{~km}$ range. Increasing the integration time with this receiver improves the result, but not enough to reach $3 \mathrm{~km}$ as we wish: $1.7 \mathrm{~km}$ are reached with an SNR of 7 when the integration time is increased to $30 \mathrm{~min}$, and $2 \mathrm{~km}$ when it is increased up to $2 \mathrm{~h}$. It is thus necessary to consider a dual receiver system.

According to the simulation, the $500 \mathrm{~mm}$ telescope with a 0.4 mrad field-of-view allows to reach $2.7 \mathrm{~km}$ with an SNR of 7, and $3 \mathrm{~km}$ with an SNR of 4.5, but this telescope is less useful in the very near range due to its slowly increasing overlap function (geometrical form factor equal to zero up to $200 \mathrm{~m} ; 0.1$ at $500 \mathrm{~m}$, and 0.5 at $900 \mathrm{~m}$ ).

The plot for nighttime measurements shows that in the absence of sky background much larger ranges can be reached: if the limit is put at $\mathrm{SNR}=7$, almost $4 \mathrm{~km}$ can be reached with 


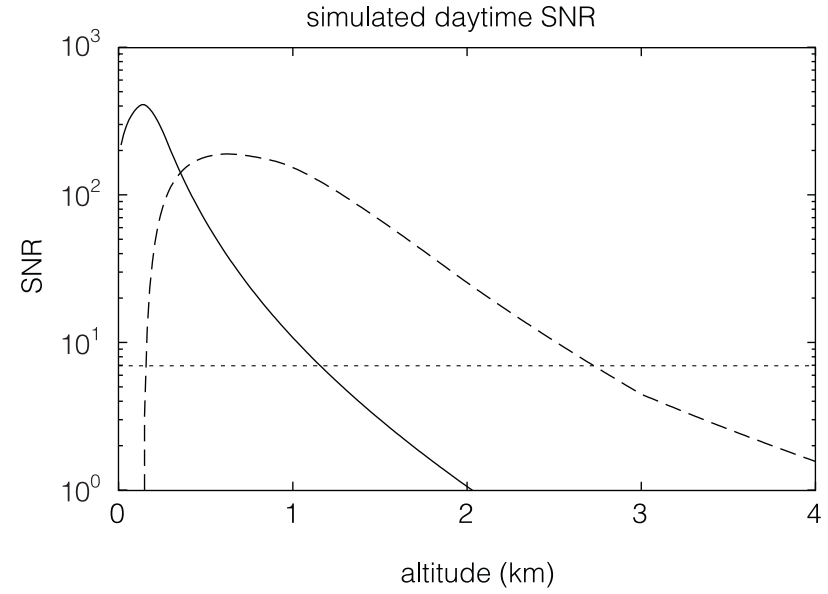

Fig. 3. Simulated SNR in daytime for 2 min integration time with the small telescope (solid line), and for 30 min integration time with the large telescope (dashed line). The thin dotted line denotes the SNR $=7$ level.

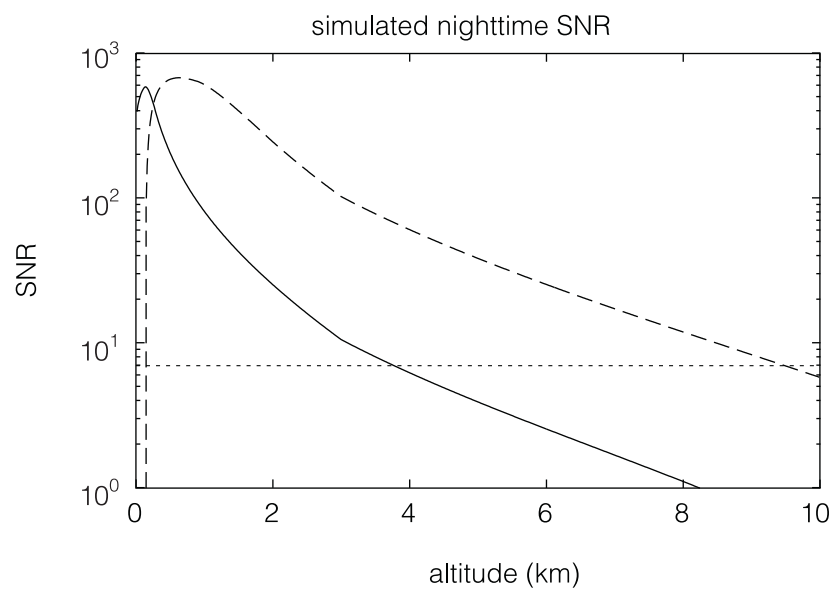

Fig. 4. Simulated SNR in nighttime (no background) for 2 min integration time with the small telescope (solid line), and for 30 min integration time with the large telescope (dashed line). The thin dotted line denotes the SNR $=7$ level.

the small receiver ( 2 min integration time) and approximately $10 \mathrm{~km}$ with the large receiver (30 min integration time).

\section{Discussion}

Besides Raman lidar, another possibility is available for water vapour measurements: DIfferential Absorption Lidar (DIAL) in the near infrared (Browell et al., 1979; Browell, 1983; Senff et al., 1994; Kiemle et al., 1997; Giez et al., 1999; Wulfmeyer, 1999; Wulfmeyer and Walther, 2001a,b). For DIAL, instrument sizing is less crucial and performance is strongly improved. The problem with DIAL is related to the narrow width of the water vapour absorption lines $(\sim 10 \mathrm{pm})$. This fact increases the experimental complexity, since even a tiny shift in the laser output wavelength causes a huge variation of the cross-section, which directly enters the DIAL equation and thus affects the water vapour profiles. The system would therefore need a certain degree of complexity, since the variations in the emitted spectrum would have to be monitored continuosly. This consideration pushed us to discard this option, since the system is going to be installed at a remote site, where it is not possible for the operator to make frequent adjustments.

When playing with models and simulations, it must always be born in mind that a real system will always behave differently than expected. However, this exercise is useful before designing a new lidar, to get an idea of the crucial parameters. This is particularly important when designing a water vapour Raman lidar for daytime operation, since with a weak signal and a large background we are in adverse conditions. Simulation parameters should not be set to unreasonably optimistic values, if one does not want to encounter deception when performing the experiment. An important element of the system is the laser source, which should be as powerful as possible. The $355 \mathrm{~nm}$ wavelength is therefore particularly suitable due to the availability of the (frequency tripled) Nd:YAG laser which permits us to reach a large output while keeping the system simple to operate. Lasers with up to $\sim 400 \mathrm{~mJ}$ energy at $355 \mathrm{~nm}$ and $30 \mathrm{~Hz}$ are available on the market, but in the simulations we limited ourselves to $325 \mathrm{~mJ}$ because we believe that it is not reasonable to operate the laser at full power. Similarly, we believe that the quantum efficiency assumed in table II is reasonable for the UV spectral range. Optical efficiency is hard to evaluate, and we therefore conservatively chose a low value. Zenith sky irradiance in the worst case was used (near noon of the summer solstice). However, despite choosing 
not excessively optimistic system constants, we must bear in mind that only experiment will yield the correct signal-to-noise ratio.

\section{Acknowledgements}

Thanks to Vincenzo Santacesaria for providing his computer code for geometrical form factor calculations.

\section{REFERENCES}

Ansmann, A., R. Neuber, P. RairouX and U. WANDinger (Editors) (1997): Advances in Atmospheric Remote Sensing with Lidar, Selected Papers of the 18th International Laser Radar Conference (Ilrc), Berlin 22-26 July 1996 (Springer-Verlag, Berlin), pp. 590.

Bisson, S.E., E. Goldsmith and M.G. Mitchel (1999): Narrow-band, narrow field-of-view Raman lidar with combined day and night capability for tropospheric water-vapor profile measurements, Appl. Opt., 38, 1841-1849.

BROWELL, E.V. (1983): Remote sensing of tropospheric gases and aerosols with an airborne DIAL system, in Optical and Laser Remote Sensing, edited by K.D. KILlinger and A. MOORADIAN (Springer-Verlag, Berlin), 138-147.

BROWELL, E.V., T.D. WILKERSON and T.J. MCILRATH (1979): Water vapor differential absorption lidar development and evaluation, Appl. Opt., 18, 3474-3483.

Burke, R.J., C.E. Helsey, S.K. Sharma, C. Kumar, N. PATEL and J.M.J. MADEY (1998): High performance FEL for the proposed PEARL research platform, $\mathrm{Nucl}$. Instrum. Methods Phys. Res. B, 144, 99-106.

Chamard, P., L. Ciattaglia, F. Monteleone and A. DI SARRA (1999): The station for climate observations at Lampedusa: greenhouse gas measurements, in WMO Proceedings of the $\mathrm{X} \mathrm{CO}_{2}$ Expert Meeting (in press).

DABAS, A., C. LOTH and J. PELON (Editors) (2001): Advances in Laser Remote Sensing, Selected Papers Presented at the 20th International Laser Radar Conference (ILRC), Vichy, France, 10-14 July 2000 (Éditions de l'École Polytechnique, Palaiseau, France), pp. 492.

Di SARRA, A., M. CACCIANI, M. CAMPANELli, P. ChAMARD, C. Cornwall, J. Deluisi, L. De Silvestri, T. Di Iorio, P. Disterhoft, G. Fiocco, D. FuÀ, P. Grigioni, W. Junkermann, F. MARENCO, D. MELONI, F. MONTELEONE and B. Olivieri (2001): Radiation, ozone and aerosol measurements at Lampedusa during the PAUR-II campaign, in IRS2000: Current Problems in Atmospheric Radiation, Proceedings of the International Radiation Symposium, St. Petersburg, Russia 24-29 July 2000 (A. Deepak Publishing), pp. 1360 .

Ellsworth, J.W., K.J. Voss, H.R. Gordon, H. Maring, A. SMirnov, B. Holben, B. SCHMID, J.M. LiVINGSTON, P.B. Russell, P.A. Durkee, P. Formenti and M.O.
ANDREAE (2000): Ground-based lidar measurements of aerosols during ACE-2: instrument description, results, and comparisons with other ground-based and airborne measurements, Tellus B, 52, 636-651.

FIOCCO, G. and L.D. SMULLIN (1963): Detection of scattering layers in the upper atmosphere $(60-140 \mathrm{~km})$ by optical radar, Nature, 199, 1275-1276.

GIEZ, A., G. EhrET, R.L. SchwIESOW, K.J. DAVIS and D.H. LENSCHOW (1999): Water vapor flux measurements from ground-based vertically pointed water vapor differential absorption and Doppler lidars, J. Atmos. Ocean. Technol., 16, 237-250.

Goldsmith, J.E.M., F.H. Blair, S.E. Bisson and D.D. TURNER (1998): Turn-key Raman lidar for profiling atmospheric water vapor, clouds, and aerosols, Appl. Opt., 37, 4979-4990.

HALLDORSSON, T. and J. LANGERHOLC (1978): Geometrical form factors for the lidar function, Appl. Opt., 17, 240244.

HINKLEY, E.D. (Editor) (1976): Laser Monitoring of the Atmosphere (Springer, Berlin).

KiemLe, C., G. Ehret, A. GIEZ, K.J. DAVIS, D.H. LENSCHOW and S.P. ONCLEY (1997): Estimation of boundary layer humidity fluxes and statistics from airborne differential absorption lidar (DIAL), J. Geophys. Res., 102, 29,189$29,203$.

LigDA, M.G.H. (1963): in Proceedings of the 1st Conference on Laser Technology, San Diego, CA, U.S. Navy ONR, 63-72.

Marenco, F., A. Di SARra and J. Deluisi (2002): Methodology for determining aerosol optical depth from Brewer 300-320 nm ozone measurements, Appl. Opt., 41, 1805-1814.

Meloni, D., F. Marenco and A. Di SArra (2003): Ultraviolet and aerosol monitoring at Lampedusa, Italy, Ann. Geophysics, 46 (2), 373-383 (this volume).

Petri, K., A. SAliK and J. CoOney (1982): Variablewavelength solar-blind Raman lidar for remote measurements of atmospheric water-vapor concentration and temperature, Appl. Opt., 21, 1212-1218.

Renaut, D., J.C. PournY and R. CAPITINI (1980): Daytime Raman-lidar measurements of water vapor, Opt. Lett., 5, 233-235.

SANTACESARia, V., F. MARENCO, D. BALIS, A. PAPAyANnis and C. ZEREFOS (1998): Lidar observations of the planetary boundary layer above the city of Thessaloniki, Greece, Nuovo Cimento, 21, 585-596.

SENFF, C., J. BÖSENBERG and G. PETERS (1994): Measurement of water vapor flux profiles in the convective boundary layer with lidar and radar-RASS, J. Atmos. Ocean. Technol., 11, 85-93.

TyNDALL, J. (1869): On the blue color of the sky, the polarization of skylight and the polarization of light by cloudy matter generally, Phil. Mag., 37, 384-394.

U.S. STANDARD ATMOSPHERE, NOAA, NASA, U.S. AIR FORCE (1976): U.S. Governement Printing office, Washington, DC, October 1976.

Vaughan, G., D.P. Wareing, L. Thomas and V. Mitev (1988): Humidity measurements in the free troposphere using Raman backscatter, Q. J. R. Meteorol. Soc., 114, 1471-1484. 
Whiteman, D.N., S.H. Melfi and R.A. FERRARE (1992): Raman lidar system for the measurement of water vapor and aerosols in the Earth's atmosphere, Appl. Opt., 31, 3068-3082.

Whiteman, D.N., G. SCHWEMMER, T. BERKOFF, H. PlotKIN, L. RAMOS-IZQUIERDO and G. PAPPALARDO (2001): Performance modeling of an airborne Raman watervapor lidar, Appl. Opt., 40, 375-390.

WULFMEYER, V. (1999): Investigation of turbulent processes in the lower troposphere with water vapor DIAL and
radar-RASS, J. Atmos. Sci., 56, 1055-1076.

Wulfmeyer, V. and C. WAlther (2001a): Future performance of ground-based and airborne water-vapor differential absorption lidar: I. Overview and theory, Appl. Opt., 40, 5304-5320.

Wulfmeyer, V. and C. WAlther (2001b): Future performance of ground-based and airborne watervapor differential absorption lidar: II. Simulations of the precision of a near-infrared, high-power system, Appl. Opt., 40, 5321-5336. 